\title{
Relatorio apresentado pelo Dr. Humberto Teixeira Cardoso ao governo da República da Colômbia - 1940
}

Em 22 de Julho de 1940.

Exm. ${ }^{\circ}$ Sr. Mnistro de Estado da Educação e Saúde.

Temos a subida honra de submeter à aprecição de V. Excia., o relatório que apresentámos ao Governo da República da Colômbia, quando concluímos alí os trabalhos de que nos achavamos incumbiobs.

Como V. Excia. poderá verificar no texto desse relatório, deixamos organizados naquele país não só a preparação dos medicamentos antilepróticos mas, tambem, a distribuição e a aplicação dos mesmos, em todo o território daquela República.

Ainda tivemos ocasião de fazer exposições teóricas e práticas aos especialistas colômbianos abordando além dos assuntos gerais ainda as pesquisas que temos realizado no campo de nossa atividade.

Pudemos observar, no tocante à organização da campanha contra a lepra, que o Governo da Colômbia vem seguindo, em linhas gerais, a orientação dada pelo Dr. Souza Araujo, com resultados já bem satisfatórios.

Ainda não foi iniciada, no entanto, a resolução do problema de assistência aos enfermos e suas famílias, especialmente na parte referente ao afastamento dos filhos sãos.

Entre as medidas que vêm contribuindo eficazmente para os resultados observados, figura em primeiro plano a centralização da direção da campanha, que é imediatamente subordinada ao Governo Central.

Seria, pois, de desejar que, ao lado do que vem fazendo o nosso Govêrno pela solução do problema da lepra em nosso território, se pudesse ter unifi-

* Recebido para publicação a 29 de agosto de 1940 e dado à publicidade em abril de 1941.

* Relatório mandado publicar por Sua Excia. o Sr. Ministro da Educação e Saude cm 29-8-1940. 
cada a orientação do combate, coisa que nos parece essencial para se obterem bons resultadios, pelo menos, na campanha profilática.

Aproveito a oportunidade para reiterar a V. Excia. os meus protestos de elevado apreço.

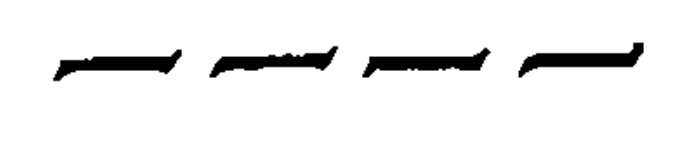

\section{Humberto Teixeira Cardoso}

Assistente técnico

Exm. ${ }^{\circ}$ Sr. Ministro do Trabalho, Higiene e Previsão Social.

Temos a subida honra de passar às mãos de V. Excia. este pequeno relatório, onde descrevemos os trabalhos que realizámos, em conexão com a luta anti-leprosa, nos diferentes Institutos oficiais.

Permita-nos, V. Excia., deixar patente a nossa admiração pelo entusiasmo e capacidade dos funcionários colombianos, o que facilitou, em muito, o nosso desempenho.

Esperando que V. Excia. julgue a contento essa nossa atividade, subscrevemo-nos com os mais elevados protestos de estima e profunda consideração.

\section{Humberto T. Cardoso}

Assistente técnico do Instituto Osvaldo Cruz

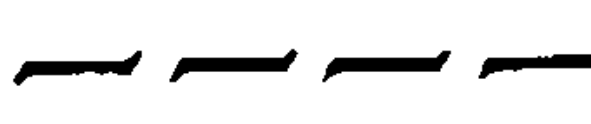

\section{APRESENTAÇÃO}

O Governo colombiano, no sentido de aparelhar o serviço anti-leproso, na parte referente à terapêtica, decidiu convidar-nos para organizar o laboratório de preparação e controle dos produtos anti-lepróticos, segundo os moldes do que dirigimos no Instituto Osvaldo Cruz, no Rio de Janeiro.

Aqui chegando, não encontramos propriamente nenhuma instalação especializada para o fim de preparo dos ésteres de óleo de chaulmugra. As primeiras operações do fabrico eram realizadas em aparelhos, feitos construir nos Estados Unidos da América, em vidro "Pyrex", segundo modelo desenhado pelo técnico colombiano Dr. Barriga Villalba. Ainda pudemos verificar que um dos aparelhos analíticos de controle, o polarimetro, não se apresentava em estado de poder fornecer dados seguros, carecendo de uma 
lâmpada de luz monocromática, do tipo de vapor de mercúrio, afim de satisfazer os seus fins.

Os medicamentos então feitos não eram distilados, mas sim brutos, sem outros tratamentos de purificação a não ser uma neutralização com cal, seguida de lavagens sucessivas com agua e eram adicionados de óleo de oliva afim de se apresentarem menos irritantes. Outro fato importante que notamos, foi o de que, para se clarear o produto, se o expunha ao sol por tempo alongado, o que é contraindicado, pois, formam-se substâncias resinosas de grande pocier irritativo. A côr do medicamento que encontrámos, era amarela e o líquido apresentava-se bastante viscoso.

Os inconvenientes que, segundo o nosso ponto de vista, se verificavam no método da fabricação então usado e no produto final, podem ser resumidos nos seguintes pontos:

1 - O método de esterificação, sem controle refratométrico, não permitia que se obtivesse uma esterificação mais extensa, sendo a causa dessa anomalia, não a qualiclade de óleo, que examinamos pessoalmente e verificamos ser muito bom, mas sim o processo de aquecimento, que náo facultava uma distribuição uniforme do calor por toda a massa líquida.

2 - A exposição prolongada à luz solar, para clarear o produto, trazia o inconveniente de aumentar o poder irritativo do medicamento;

3 - A ausência dos tratamentos posteriores de purificação, como distilação e vaporização, que reputamos essencialmente necessários;

4 - A não adição de substâncias anti-irritantes, como o iodo e o creosoto, do modo indicado na técnica apresentada ao Congresso Internacional do Cairo, em 1938 ;

5 - A adição do óleo de oliva puro diluia o produto terapeuticamente ativo, baixando sua concentração a cerca de $70 \%$.

Assim, foi necessário instalar um laboratório especial para os fins de preparação, o qual organizámos como se segue:

1 conjunto esterificador, constituido por tres potes de argila refratário, cada um de vinte litros;

1 conjunto lavador, constando de um tanque de tijolos, forrado de ladrilhos vidrados brancos, com as juntas tomadas com cimento a prova de ácidos; este conjunto será completado com a chegada, mais tarde, de dois tanques de aço inoxidavel, encomendados ao Rio de Janeiro;

1 distilador, de aço inoxidavel, de capaciciade para vinte ou trinta litros diários, constuido no Rio de Janeiro, segundo o modelo Cole \& Cardoso: 
1 aparelho enchedor de ampolas, de alumínio.

Junto a este relatório, no anexo primeiro, encontra-se a descrição do método de fabricação adotado, com pormenores técnicos e, nas plantas I, II e III desse trabalho, indicamos algumas caracteristicas dessas instalações.

Ainda examinamos os aparelhos, de marca Podbielniak, dos Estados Únidos da América, que encontrámos no Instituto Nacional de Higiene Samper-Martinez, adquiridos para o fim especial de comporem a nova instalação de chaulmugra.

Um dêles, a bomba centrifuga, não nos parece adaptada aos serviços para que foi adquirida. O seu alto preço, a dificuldade de manobra, principalmente por subalternos, o rendimento escasso quando distilando ésteres e, acima de tudo, o custo da operação, parecem constituir razões bastantes para sua contra-indicação, pois, nem mesmo em qualidade, o produto final obtido é superior ao que se obtem pelo procedimento que empregamos.

Quanto ao outro aparelho, um fracionador de alta precisão, é bastante indicado para pesquizas neste ramo da química, como aliás temos provado com a série de trabalhos que publicamos sobre este particular.

Outra parte de nossa atividade foi empregada em pequeilas pesquizas no Instituto Lleras Acosta e no Dispensário de Cundinamarca, referentes às propriedades dos medicamentos, com comprovações histológicas. Nestas pesquizas colaboraram a Dra. Rita A. A. Cardoso, do Instituto Osvaldo Cruz e o Dr. Leopoldo Albarracin do serviço anti-leproso da Colômbia. Agradecemos aos srs. Drs. Patiño Camargo e Sanchez Herrera, respectivamente Diretor e chefe da secção de anatomia patclógica, desse Instituto Lleras Acosta e Dr. Gomez Plata. Diretor do Dispensário, as facilidades que nos proporcionaram.

Ainda, de acordo com o programa organizado pelo serviço anti-leproso, para a 2. ${ }^{\text {a }}$ Conferência dos leprologistas colombianos, coube-nos fazer uma palestra e demonstrações práticas, nos dias 1 e 2 de Abril, nos Institutos Lleras e Samper-Martinez.

Assim, tendo procuracio corresponder aos encargos da missão que nos foi confiada, esperamos que os nossos trabalhos possam resultar em ajuda para a campanha anti-leprosa na Colômbia. Fortalece esta nossa pretensão o fato de que a questão dos medicamentos anti-lepróticos, no país, já atıngia gráos de verdadeiro problema social. Era o ponto mais vulneravel da organização atual da campanha na Colômbia, que, embora contando com a magnífica lei que impede a preparação e venda de quaisquer produtos semelhantes, sentia-se obrigada a uina tolerância que doravante não mais subsistirá. 
A organização nacional de higiene, cujo fim é velar carinhosamente pela saude pública, pode passar agora a uma ofensiva decisiva, contando com um medicamento que, em qualidade, é o melhor que se pode conseguir e cujos preços de obetenção representam frações pequeníssimas dos dos produtos comerciais, de propriedades inferiores.

Desloca-se, assim, o problema da lepra na Colômbia, para uma outra etapa que acreditamos poderá ser vencida, convencendo-se todos de que o capital empregado atualmente será uma inversão a altos juros.

Parece-nos que, resolvida a construção das colônias e continuada a orientação atual da campanha, com a maior intensidade, possivel, a lepra não será mais um problema na Colômbia dentro de 15 a 20 anos.

Não queremos terminar esta exposição antes de formular uma sugestão para que se institua um intercâmbio mais intenso entre Brasil e Colômbia. permitindo uma visita anual dos leprologistas colombianos à organização anti-leprosa do nosso país. Seria, ao nosso ver, de grande utilidade, tanto pelo lado técnico, pois a mudança de ambiente e métodos sempre proporciona a aquisição de idéias novas, como tambem pelo lado moral, permitindo o estabelecimento de incentivo para os que colaboram em tão árdua campanha.

Terminando, queremos expressar os nossos profundos agradecimentos pelas inúmeras e excessivas atenções que recebemos, indistintamente, de todos aqueles com que tivemos o prazer de manter contato.

\section{ANEXO PRIMEIRO}

\section{A FABRICAÇÃO DOS MEDICAMENTOS DE CHAULMUGRA PELO PROCESSO COLE-CARDOSO}

\section{Por HUMBERTO T. CARDOSO}

Do Instituto Osvaldo Cruz, Rio de Janeiro - Brasil.

Como parte essencial de nossa missão na Colômbia, estava, organizar uma instalação para o fabrico de medicamentos anti-lepróticos de chaulmugra, cujas qualidade de tolerância e não irritabilidade permitissem o estabelecimento de um tratamento racional, padronizado e, sobre tudo, mais humanitário. O método de preparação é o de Cole-Cardoso (1), sendo mais atualizada a parte de instalação, o que permite melhores condições de trabalho. 
Com o fim de divulgação e, mesmo, para modernizar a nossa primeira publicação de 1936, vamos descrever o aparelhamento e o método que hoje já se está empregando no Instituto Nacional de Hygiene Samper-Martinez, em Bogotá, Colômbia.

As operações que se levam a efeito na preparação dos ésteres de chaulmugra podem ser esquematizadas na seguinte chave:

Esterificação

$$
\text { Propriamente dita }
$$

Libertação dos sub-produtos e resíduos

Distilação

Neutralização

Vaporização

Iodação ou creosotação

ESTERIFICAÇÃO : Nesta operação deve-se ter em conta vários dados analíticos sobre o óleo empregado e fazer o controle refratométrico, para obter maior rendimento.

O óleo usado é o de Hydnocarpus Wightiana, cujas caracteristicas fisicas e quimicas são as seguintes :

$$
\begin{aligned}
& { }_{\mathrm{D}}-1.4776 \text { a } 25^{\circ} \mathrm{C} . \\
& {[\alpha]_{\mathrm{D}}=50.8^{\circ}} \\
& \text { Acidez }-5.4 \% \text { em ácido oleico. } \\
& \text { I. iodo }=99.2 \text { (método de Hanus). } \\
& \text { I. sap. }=204 \\
& \text { Densid. }=0.953 \text { a } 25 / 25^{\circ} \mathrm{C} .
\end{aligned}
$$

Aparelhagem: Na planta I vê-se como são organizados os esterificadores : o recipiente de argila refratária é colocado dentro de uma câmara revestida de tijolos, tambem de argila refratária, e tampado por uma chapa de ferro, completando-se o vedamento por tiras de borracha vulcanizada, retirada de câmaras de ar velhas, dos pneumáticos de auto-caminhões.

Nessas câmaras de argila refratária ha vapor circulante livre, ficando os potes inteiramente banhados por ele, o que permite um aquecimento muito uniforme e enérgico.

Cada pote é dotado de um condensador de refluxo, de ferro galvanizado, que tem agua fria circulante. Os condensadores de refluxo são mantidos por umas braçadeiras de ferro que se podem deslocar sobre um eixo e, assim, permitir a carga e descarga. 


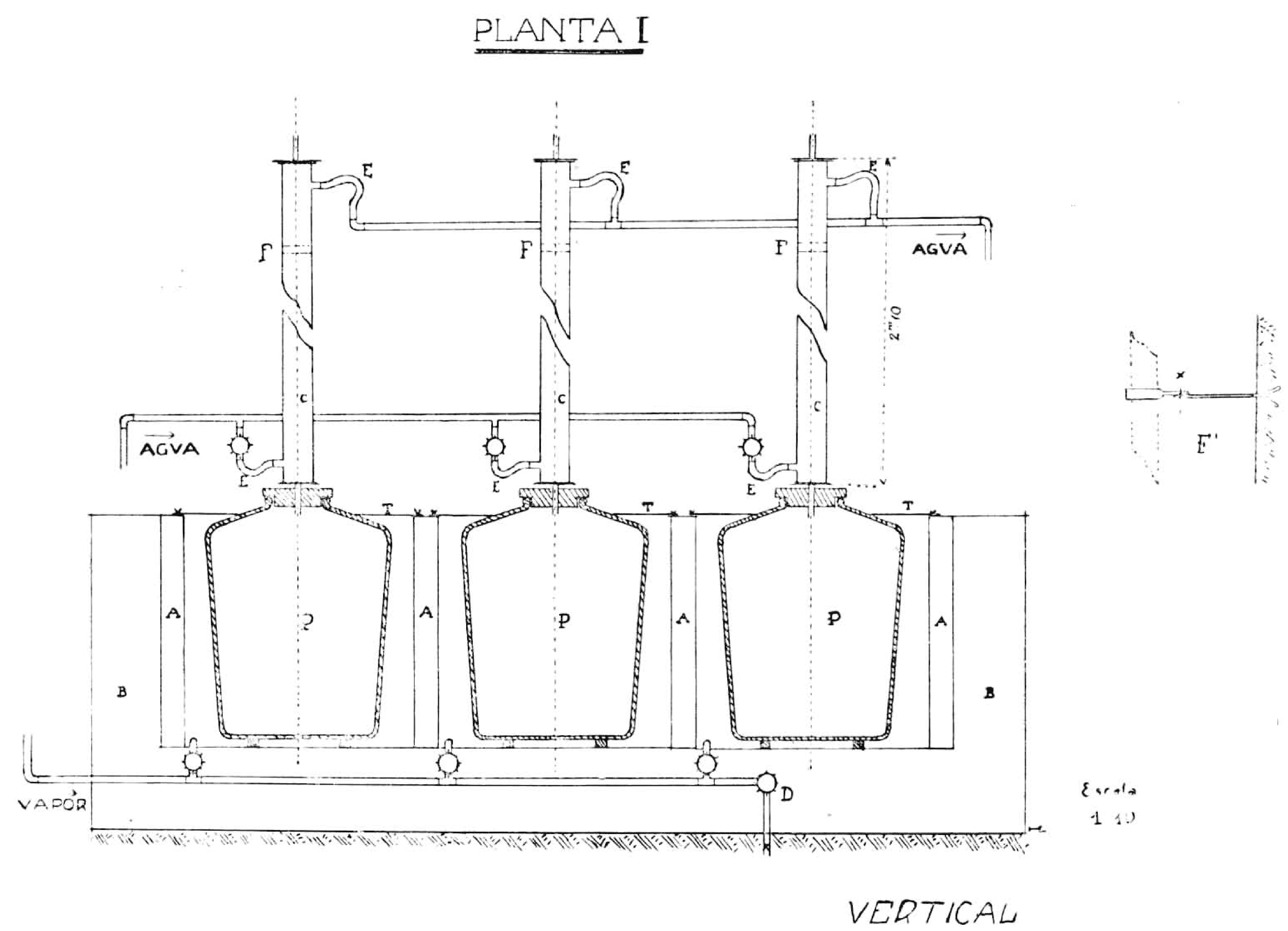

\footnotetext{
A - revestimento interior das câmaras com tijolos refratários;

B - parede exterior de tijolos comuns ;

$\mathrm{P}$ - potes de argila refartária, vidrados por dentro, onde se processa o estcrificação;

C - condensadores de refluxo, de ferro galvanizado;

D - torneira para descarregar a agua condensada na instalação ;

$\mathrm{T}$ - tampas de ferro, vendo-se as borboletas que as prendem;

E - Ligação da água aos condensadores, por tubos de borracha;

F - braçadeiras de ferro para manterem os condensadores na posição vertical ;

F' - pormenor mostrando o arranjo das braçadeiras de ferro, de modo a permitir o giro horizontal dos condensadores de refluxo.
}

Operação: A carga dos esterificadores deve ser f́eita em quantidade relativa às suas capacidades, mantendo a relação de uma parte de óleo para uma parte de álcool a $95 \%-100 \%$ e $5 \%$ de ácido sulfúrico, concentrado a $66^{\circ}$ Bé. (den- 1.84), sobre o total da mistura óleo-álcool, como catalizador. Tanto o álcool como o ácido sulfúrico são do tipo "comercial" devendo, no entanto ter -se a precaução de controlar sempre suas concentrações e aten tar bem quanto à pureza dos mesmos. 


\section{PLANTA II}



HORIZONTAL

A - revestimento de tijolos refratários, vendo-se a localização dos parafusos de fixação das tampas de ferro;

$\mathrm{B}$ - revestimento de tijolos comuns;

C - câmaras de circulação de vapor.

A carga, que deve ser sempre feita de véspera, sofre um aquecimento contínuo, por um número de horas que fica ao redor de oito, e de tal maneira feito que permita uma ebulição agitada da massa líquida, por todo esse tempo. O número de horas deverá ser fixado pela curva dos índices de refração. O óleo tem este índice muito mais elevado que o dos ésteres e, assim, quanto maior fôr a porcentagem de ésteres mais baixo será o índice de retração da mistura. Na instalação ora organizada verificámos que oito horas são suficientes uma vez que se mantenham as mesmos concentrações do álcool e áciảo sulfúrico, que empregamos. (Veja gráfico I.)

Llma vez cessado o aquecimento, deixa-se a mistura em repouso por uma noite, decanta-se na manhãa seguinte, desprezando a camada inferior, onde se encontram o álcool excedente, agua e ácido sulfúrico, e a glicerina deslocada. A camada superior constitue-se dos ésteres brutos, que passarão, a seguir, por lavagens sucessivas com agua quente a $80-90^{\circ} \mathrm{C}$., até que fiquem livres das impurezas, especialmente do ácido sulfurico empregado como catalizador. Geralmente, quatro lavagens são o bastante. 
DISTILAÇ̃̃O : Esta operaçãc tem por fim separar os produtos inati vos, de elevado ponto de ebulição e o óleo, não transformado, dos ésteres brutos.

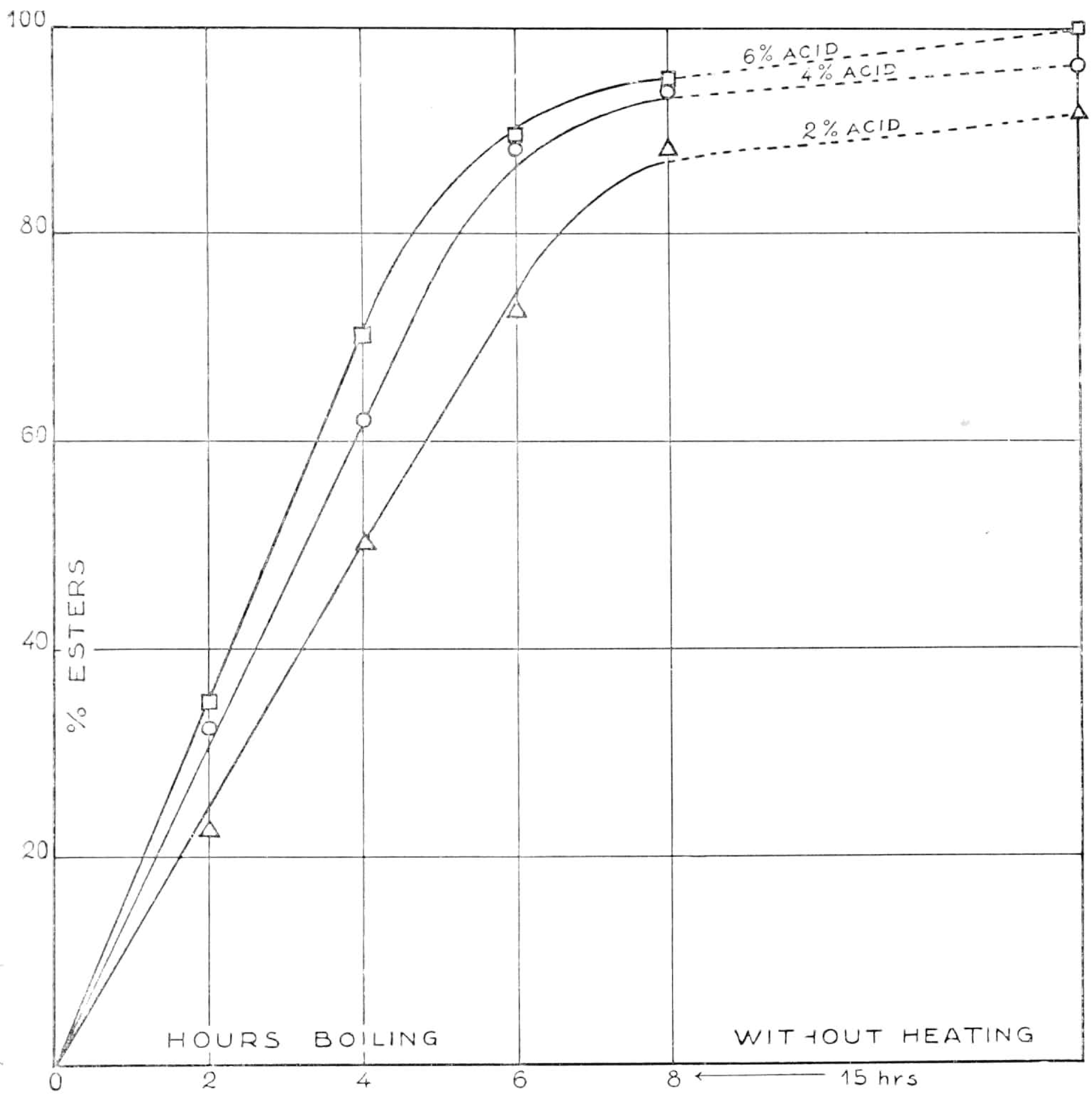

Text-fig. 1. Curves showing varation of rate of esterification of chaulmoogra oil with different concentrations of sulphuric acid.

Reimpresso do "Int. Jour. of Lep." — Vol. 4, pgs. 459 (1936)

Como se trata de uma operação feita com alta temperatura, ha uma consequente decomposição, o que faz com que o prodıto, depois de distilado, apresente uma acidez livre de 3-7 \%o em ácido oleico.

A distilação é realizada num aparelho especial de aço inoxidavel (planta III), com frascos purificadores, de vidro, interpostos entre o distilador e a 
bomba de vácuo. Esta deve ser de bastante capacidade para permitir que a distilação se efetue a uma temperatura mais baixa $e$, consequentemente, mais rapidamente. Isto melhora muito a qualidade do produto e o rendimento, uma vez que um maior tempo de aquecimento corresponde a uma maior decomposição.
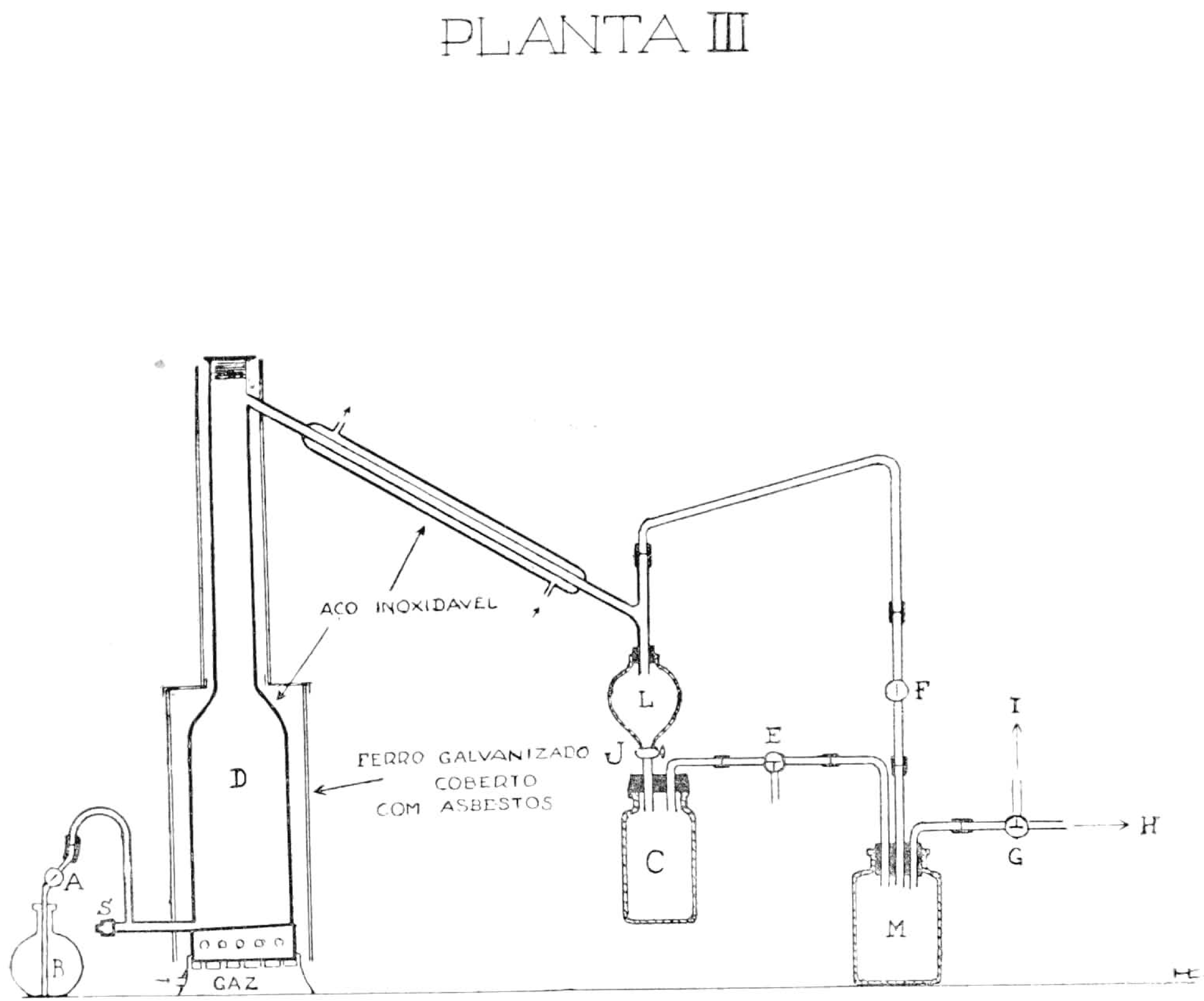

D - distilador em aço inoxidável, em peça inteiriça até o funil de decantaç̃o:

B - frasco de vidro, para a entrada dos ésteres brutos:

C - frasoo de vidro, para a coléta dos ésteres distilados:

L - funil de decantação, de vidro "Pyrex", de preferência;

M - frasco de vidro, destinado a reter os produtos mais voláteis:

H - ligação para a bomba de vácuo ;

I - ligação para o manômetro .

Nota: a) o fundo do aparelho é inclinado de modo a permitir o escoanento do resíduo, sem mover o aparelho:

b) a tampa da coluna de fracionamento é adaptada por meio de uma rosca, vedada por massa de litargírio:

c) pendente dessa tampa, dispõe-se uma espiral de aço inoxidável, destinada a fazer maior contato para os vapores:

d) as torneiras A, E, F e G devem ser de vidro "Pyrex", e muito bem esmerilhadas. 
Para se evitarem entradas de ar no aparelho, é aconselhavel, além de se fazerem as conexões vidro a vidro, ainda cobrir o tubo de borracha de cada conexão com verniz Duco. Do mesmo modo, todas as rolhas de cortiça devem ser embebidas com esse verniz.

O aparelho consta, como se vê na planta III, de uma parte de distilação propriamente, em aço inoxidavel, e outra de vidro, para receber o produto, impedir a passagem de maior quantidade de substâncias voláteis à bomba de vácuo e, por fim, um vacuômetro para indicar a pressão em que se distila.

Operação: Carrega-se o aparelho, com a bomba de vácuo trabalhando, com dois litros de ésteres brutos, pela torneira A, e logo se acende a chama de gás. Empregam-se uns 25-30 minutos, até que principie a distilar o que uma vez verificado, deve-se fazer compensar a quantidade distilada pela entracia lenta de mais ésteres brutos pela torneira $A$. Com o fim de facilitar a obtenção desse equilibrio, os frascos $\mathrm{B}$ e $\mathrm{C}$ devem ter a mesma capacidade, próxima de um litro.

Vamos resumir nos itens seguintes o manejo do aparelho e os cuidados que se devem tomar:

1 - Ligar a bomba de vácuo e a agua do condensador;

2 - Carregar com dois litros de ésteres brutos, lavados e secos, por meio da torneira $\mathrm{A}$;

3 - Acender o aquecedor: Quando se inicie a distilação:

4 - Fazer entrar pela mesma torneira A mais ésteres brutos, na mesma proporção em que estejam distilando:

5 - Ao fim do dia de distilação, retirar o resíduo pela saída $\mathbf{S}$;

6 - Para substituir o frasco $C$, quando esteja cheio, gira-se a torneira E, no sentido de permitir a entrada de ar só para esse frasco; antes de repô-lo, vasio, fechar a torneira F, colocar o frasco na posição original, voltar a torneira $\mathrm{E}$ á primeira posição e, logo que a pressão se tenha normalizado, reabrir a torneira $F$.

\section{CUIDADOS :}

7 - A torneira J deve ser mantida normalmente fechada, pois, si por qualquer anormalidade suceder saír um produto mais impuro, não se perderá a parte já distilada ; 
8 - Para economizar tempo e facilitar a distilação, os ésteres já devem entrar um pouco aquecidos;

9 - Cuidar sempre da pressão da distilação que, no caso de não se mostrar sempre por volta de $10-12 \mathrm{~mm}$. $\mathrm{Hg}$., indica que ha entrada de ar no aparelho. Retomar todas as juntas e rolhas de cortiça com verniz Duco.

NEUTRALIZAÇÂO: Embora a đ̛̉istilação tenha uma grande importância quanto à qualidade do produto, em relação às substâncias terapêuticamente ativas, tem, por outro lado, a desvantagem de promover o aparecimento de corpos irritantes, de carater ácido, resultantes das decomposições dos ácidos graxos, por oxidação.

Torna-se, pois, imprescindivel o tratamento com hidróxido de sódio, para libertar os ésteres desses produtos. Esta operação que chamamos neutralização, deve ser considerada como a mais importante de todas as que se levam a termo na praparação dos ésteres de chaulmugra.

Uma vez adicionado o álcali aos ésteres, o sabão formado tende a dissolver-se na agua quente que forma a camada inferior e, nesse movimento, arrasta todas as impurezas presentes, inclusiveis matérias corantes. Assim o produto final, além de neutro, ainda se apresenta praticamente incolôr. Os valores da acidez que se encontram para os ésteres, depois de neutralizados, variam entre 0.02-0.08\%, em ácido oleico.

Operação: É levada a efeito em tanques de aço inoxidavel, com dupla parede e circulação de vapor, de 250 litros de capacidade.

Coloca-se nesses tanques a quantidade de agua quente a $80-90^{\circ} \mathrm{C}$., correspondente a volume igual do ésteres que se vão neutralizar. Adiciona-se com agit ‘ção forte, o álcali, que deve ser soda cáustica do tipo "comercial", para formar uma solução a $1 \%$. Revolve-se toda a massa líquida para distribuir bem o álcali, juntam-se os ésteres com agitação enérgica e, em seguida, deixa-se repousar por vinte e quatro horas. Findo esse tempo, retira-se, pela válvula inferior, a camada aquosa (que é exatamente a de baixo). Adiciona-se novamente outro volume igual de agua quente a 80 $90^{\circ} \mathrm{C}$., promovendo-se, desta vez, uma agitação branda da massa líquida, para evitar uma emulsificação intensa, que dificultaria a separação nas vinte e quatro horas consecutivas. Esta lavagem é repetida por mais tres ou quatro vezes, espaçadas sempre de um dia.

VAPORIZAÇÃO : Desde que estejam neutros, os ésteres ainda devem ser desodorizados. Esta operação traz, simultaneamente, a vantagem de 
diminuir ainda mais as qualidades irritantes do produto pois as substâncias voláteis são, normalmente, aldeidos hidroaromáticos e corpos semelhantes.

A vaporização consiste em fazer borbulhar, nos ésteres neutros, vapor dagua, por duas horas consecutivas. Isto pode ser feito em potes de argila refratária, semelhantes aos empregados para a esterificação e fazendo penetrar o vapor por um tubo forte, de vidro, que mergulhe até quasi o fundo do vaso.

Deixam-se repousar por umas quatro horas e, depois de decantados, são filtrados.

IODAÇÃO OU CREOSOTAÇ̃̃O: Passados os ésteres por todas as fases precedentes, estão prontos para receber as substâncias anti-irritantes. $O$ iodo é bem mais aconselhavel, pois, além de tirar totalmente a irritação dos ésteres, ainda é dotado de atividade terapêutica própria. O creosoto já não permite obter senão uma medicação apenas toleravel, acrescendo a circunstância de que é contra-indicado para as infiltrações intra-dérmicas.

A iodação é realizada em recipientes de ferro esmaltado ou de aço inoxidavel e sempre com quantidades que permitam obter uma distribuição bem uniforme de calor.

A temperatura é o fator mais importante nesta operação. Os ésteres são aquecidos a $140^{\circ} \mathrm{C}$., com pequena agitação, para igualar o aquecimento. Nesta ocasião, adiciona-se o iodo necessário para fazer $0.5 \mathrm{grs} . \%$ (5 grs./ litro). A temperatura eleva-se imediatamente a $145-150^{\circ} \mathrm{C}$., graças às reações que se processam então. Desse momento $\mathrm{em}$ diante, contam-se trinta minutos exatamente, durante os quais deve-se manter a temperatura a $150^{\circ} \mathrm{C}$.

Depois resfria-se o produto a uns $70^{\circ} \mathrm{C}$., para filtrá-lo. A distribuição em ampolas e seu fechamento devem ser realizados imediatamente após.

Para a iodação, indicamos o emprego de 15 litros de ésteres de cada vez, em recipientes de ferro esmaltado ou de aço inoxidavel, de $36 \mathrm{cms}$. de diametro. O iodo deve ser resublimado e de marca garantida para análise química.

A creosotação não carece de maiores cuidados. Si o creosoto, que deve ser do tipo "de faia", não fôr bastante claro, é aconselhavel distilá-lo antes.

Pode-se empregar qualquer volume de ésteres, o creosoto é adicionado na proporção de $4 \%$ e depois filtram-se antes de distribuílos em ampolas. 
CUSTO DE OBTENÇÃO DO MEDICAMENTO QUE ORA SE FABRICA : Vamos expôr, a seguir, a estimativa do custo de obtenção dos medicamentos de chaulmugra pelo processo que acabámos de instalar.

\section{LISTA DOS PREÇOS DAS MATÉRIAS PRIMAS E DROGAS EM GERAL, FORNECIDAS PELO INSTITUTO NACIONAL DE HYGIENE - SAMPER-MARTINEZ}

\section{(Pesos Colombianos)}

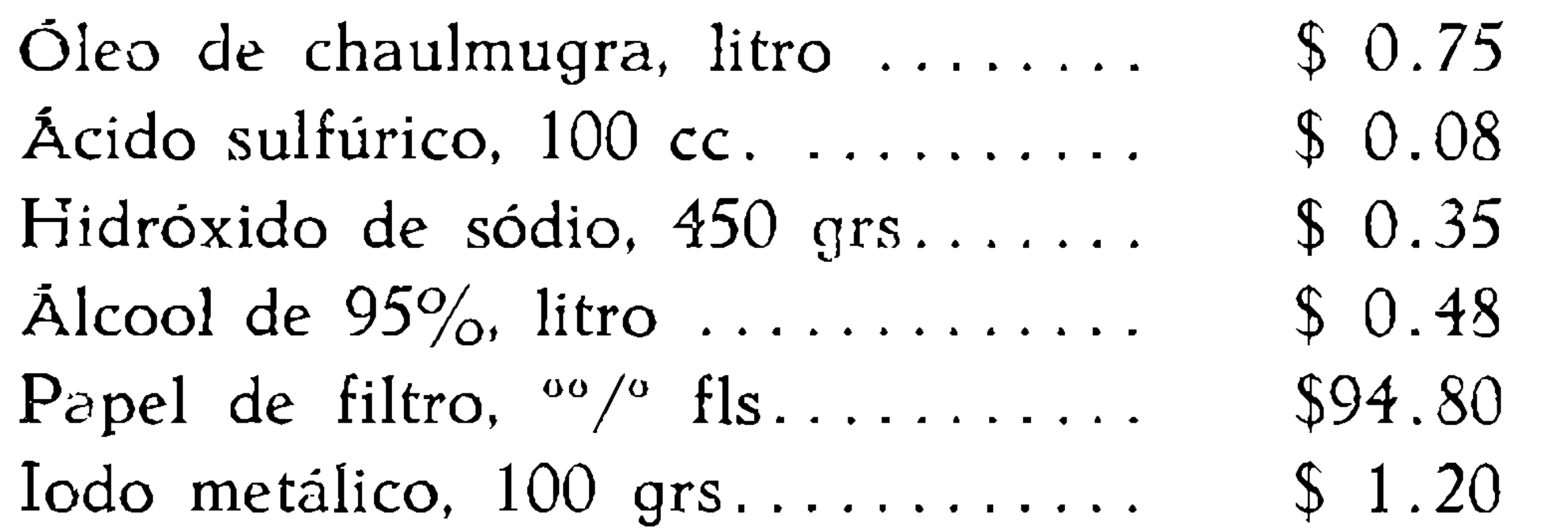

Pessoal empregado no serviço:

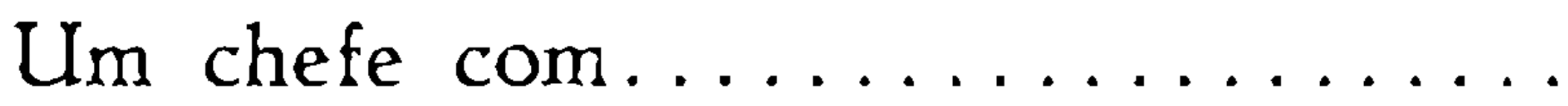

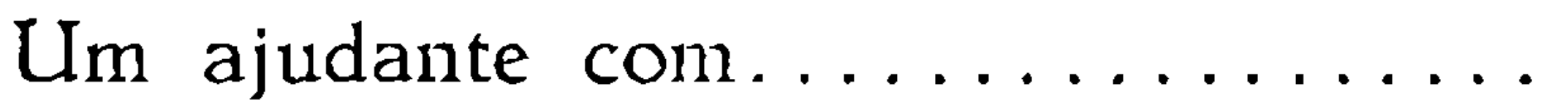

Três serventes com.

$\$ 300.00$ mensais.

$\$ 60.00$ mensais.

$\$ 40.00$ mensais, cada.

1. Cálculo. Preço do material por uma tonelada:

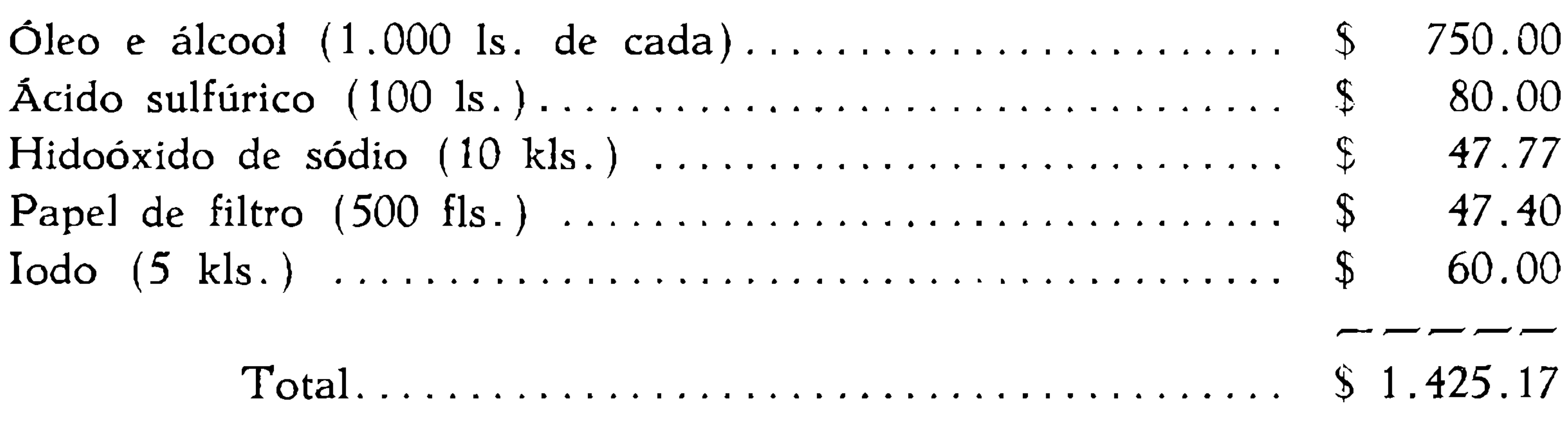

2. Cálculo: Perdas por manipulação $25 \%$ :

Por tonelada

3. Cálculo : Pessoal, por ano :

4. Cáculo: Vapor, gás, eletricidade, etc :

Vapor e gás, por 2.000 horas.................... \$ $\$ 300.00$

Eletricidade, por 2.000 horas $\left(2 \frac{1}{2}-\mathrm{HP}\right) \ldots \ldots \ldots \ldots \ldots \$ 40.00$

Total

$\$ 340.00$ 
5. Cálculo: Depreciação da instalação, $10 \%$ :

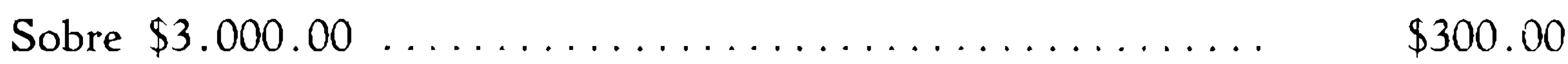

6. Cálculo: Interesse de $5 \%$ :

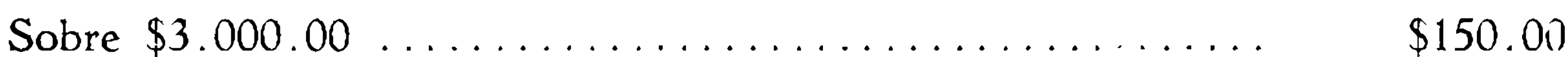

Cálculo final :

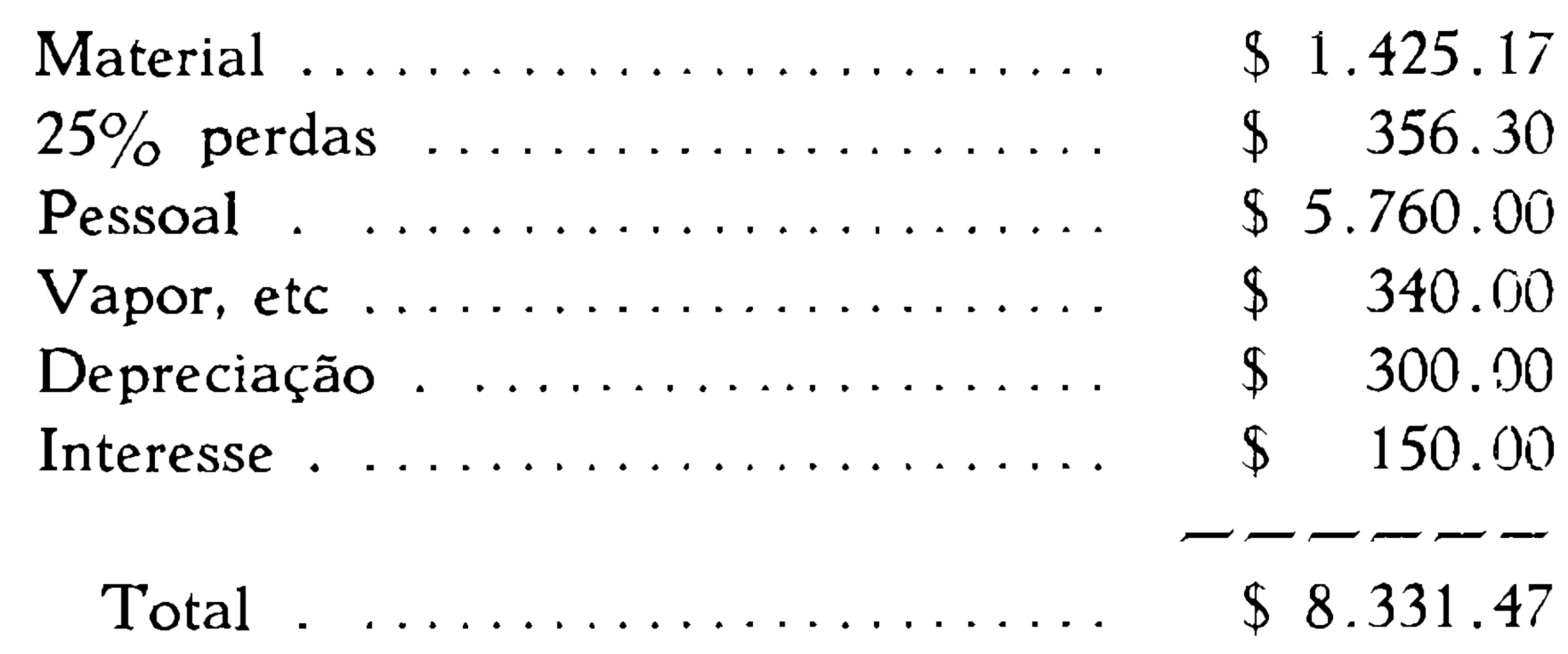

Em ampolas: de $5 \mathrm{cc}$

$\$ 8.50$ (ésteres) (aproximando).

$\$ 4.00$ (ampolas)

$\$ 12.50$ o litro, ou 1 ampola $\$ 0.06,3$

Em ampolas: de $100 \mathrm{cc}$

$\$ 8.50 \quad$ (ésteres)

$\$ 3.00$ (ampolas)

$\$ 11.50$ o litro, ou 1 ampola $\$ 0,11,5$

Resumindo :

1 ampola de $5 \mathrm{cc}$. custa.................. \$0.06.3

1 ampola de $10 \mathrm{cc}$. custa................. \$ $\$ .11,5$

Si, em vez de uma tonelada por ano, produzir a mesma instalação duas. os preços acima transformam-se em:

$\begin{array}{ll}1 & \text { ampola de } 5 \mathrm{cc} \ldots \ldots \ldots \ldots \ldots \ldots \ldots \ldots \ldots \ldots \ldots \ldots \ldots \ldots \ldots \ldots \ldots \ldots \ldots \ldots \ldots \ldots \ldots\end{array}$

É conveniente notar que, a instalação que acabamos de fazer, tem capa cidade até para mais de duas toneladas por ano.

CONTROLE DOS MEDICAMENTOS: 1 - Provas físicas e quimicas :

Estas são muito necessárias, pois, com a reunião dos seus dados, ao fim de certo tempo, poder-se-á ter uma idéia da constância da qualidade do produto. Os dados mais importantes, que se devem tomar, são os três 
seguintes: a) índice de acidez livre, expressa em ácido oleico \%; b) poder rotatório, que indicará a quantidade de substâncias terapeuticamente ativas, presentes; c) indice de refração.

Todos esses dados ficam registados em livros próprios e, qualquer dúvida que surja com o medicamento, será esclarecida mediante a menção do número do lote, que aparece em cada caixa de ampolas.

2 - Provas intradérmicas: Estas provas são feitas com cada novo lote, sem o resultado das quais não terão saida para o consumo.

Consistem em fazer uma infiltração intradérmica de $0.1 \mathrm{cc}$. dos ésteres iodados, usando agulha de $3 \mathrm{~mm}$., do tipo Muir, e uma seringa de $1 \mathrm{cc}$., graduada em centésimos. A leitura é feita 24 horas depois. Quando houver formação de pápula é conveniente verificar se não há intolerância pessoal, o que pode ser feito procurando uma pessoa sabidamente tolerante.

\section{COMPROVAÇĀO DA QUALIDADE DOS NOVOS PRODU-} TOS: Uma vez preparados os novos ésteres, iniciamos as provas de irritabilidade. Como de costume, a primeira prova é feita em nós mesmos e, em seguida, em pessoas sãs, no laborat6rio. Mostrou-se ótimo, o produto e, então, começamos as experiências com os enfermos, no Dispensário Antileproso de Cundinamarca. Estas observações serão continuadas e empliadas pelos ilustres médicos Drs. Gomez Plata e Leopoldo Albarracin, respecíivamente, diretor do Dispensário e chefe de controle dos medicamentos. Até o momento, não encontrámos nenhuma prova contra a boa qualidade desses ésteres iodados.

Ainda fizemos provas em coelhos, comparando os novos ésteres com os que se usavam antes, do tipo 7, lote 173 .

Nas experiências prévias, em 4 animais, somente um apresentou uma irritação no local de infiltração com os ésteres iodados. Nos demais. nada foi possivel verificar.

Nos pontos infiltrados com ésteres creosotados, preparados por nosso procedimento, formaram-se pápulas de 0.3 a $0.5 \mathrm{~mm}$. de diâmetro Nos locais das infiltrações com os ésteres antigos encontramos pápulas de diâmetro variando entre $1.5 \leftarrow 2.5 \mathrm{~mm}$.

Retiramos material para biópsias, desses pontos, e foram feitos cortes histológicos, no laboratório de anatomia patológica, do Instituto Lleras Acosta.

Revelaram esses cortes uma ação inflamatória inespecifica $\epsilon$, a não ser pelos diâmetros dos eritemas, macroscopicamente determinados, não se 
poderiam distinguir os produzidos pelos ésteres creosotados dos ésteres antigos, do tipo 7 .

A conclusão destas primeiras observações parece-nos ser a de que os agentes irritativos eram os mesmos nos produtos, com a diferença de que, nos antigos, existiam em quantidades extremamente grandes.

\section{ANEXO SEGUNDO}

\section{RESUMO DA PALESTRA FEITA AOS LEPROLOGOS COLOMBIA- NOS REUNIDOS EM BOGOTA EM 1-4-1940}

\section{Humberto T. Cardoso}

PEQUENA INTRODUÇÃO: Os povos mais primitivos de nossa era já tinham a noção da capacidade terapêutica de certos óleos, retirados de plantas tropicais, em relação à lepra, como tambem os nativos da China e os Incas, do Perú, já empregavam produtos vegetais contra a malária.

As primeiras noções que temos do emprêgo do chaulmugra referem-se às folhas e frutos da espécie Taraktogenos Kurzii, KING, encontradas principalmente na história da religião de Buddha, por volta do Sec. VI, A. D., Entretanto, não é possivel afirmar que já conhecessem o óleo de chaulmugra.

Alguns autores como SEN, JOSEH e ROGer pretendem, referincio-se a escritos dos anos 100 a 400, A. D., de velhos médicos indianos, que se en. contram citações ao óleo de chaulmugra, mas isto não parece muito certo.

Da China, as primeiras informações positivas sobre o emprêgo do chaulmugra são obtidas de escritos de médicos chinezes, que datam dos anos 1270-1367, A. D. A propriedade específica do óleo para a lepra foi descrita por um médico chinez célebre, Nu Tran-Men, em 1515, e, nos trabalínos enciclopédicos de Li-Shin-Chen, Pen-ts'ao-kang-mu, nos anos de 1552-1578. encontram-se indicações sobre o uso terapêutico e a importação de sementes de Hydnocarpus anthelmintica, do Sião, Indo-China, China e terras visinhas. com o nome de "Ta-fung-tse" (sementes de lepra).

Por sua vez os persas, em 1771, já anunciavam o emprêgo desse óleo na lepra.

Assim se foi generalizando o uso do óleo de chaulmugra, nome que então não mais significava uma simples espécie, mas espécies que tinham a propriedade de fornecer produtos com atividade contra a lepra. Por esta ocasião já era conhecida, além das espécies Taraktogenos Kurzii e Hydno- 
carpus anthelmintica, a Hydnocarpus Wightiana, hoje conhecida mundialmente, originária da India, com o nome nativo de Kavatel.

Atualmente são muitas as espécies conhecidas e produtoras de óleos com as mesmas propriedades curativas. Todas se grupam sob o nome "Flacourtiaceae" e distribuem-se em dois grandes grupos: Hydnocarpus e Oncoba. No primeiro encontram-se dois gêneros importantes: Hydnocarpus e Taraktogenos, enquadrando a maioria das espécies hoje usadas. $O$ grupo Oncoba tem como gêneros importantes Oncoba e Carpotroche, e outros dois Lindackeria e Mayna, sendo estes três últimos dotados de muitas espécies, todas nativas na América do Sul, no Brasil. São elas: no gênero Carpotroche: C. Brasiliensis, Endl., C. amazonica, Mart., C. grandiflora, SpruCE, C. longifolia, Benth, C. integrifolia, Kuhlmann; no gênero Lindackeria: L. maynensis, Endl., L. paraensis, Kuhlmann, L. latifolia, Benth, L. pauciflora, Benth, L. ovata, Benth; no gênero Mayna: $M$. odorata, Aubl.

COMPOSIÇÃO DOS ÓLEOS : Os óleos que mais interêsse apresentam, para o estudo da composição, são forçosamente os que se empregam mais largamente. São eles: Hydnocarpus Wightiana, Hydnocarpus anthelmintica, Taraktogenos Kurzii, Carpotroche Brasiliensis e Oncoba echinata, sobre os quais tambem dedicámos uma série de trabalhos analíticos, publicados no "Journal of the American Chemical Society".

Até 1904, quando Power iniciou o estudo da composição desses óleos, nada em definitivo era conhecido sobre os seus verdadeiros princípios ativos. Power e Gornall, em 1904, e em colaboração com Barrowcliff, em 1905, puzeram a descoberto dois desses principios ativos : o ácido chaulmúgrico, $\mathrm{C}_{18} \mathrm{H}_{32} \mathrm{O}_{2}$, e ácido hidnocarpico, $\mathrm{C}_{16} \mathrm{H}_{28} \mathrm{O}_{2}$. Dessa data até 1938 pouca coisa se fez e, mesmo nada de maior valor foi conseguido, em vista das dificuldades encontradas para o isolamento dos ácidos graros constituintes desses óleos. Em 1937, na sequência dos trabalhos que vinhamos realizando com o Dr. Howard I. Cole, na seção de química do Centro Internacional de Leprologia, no Rio de Janeiro, adaptamos um aparelho fracionador de gasolina ao estudo analítico dos ésteres etíticos dos ácidos graxos desses óleos. Por este procedimento nos foi possivel obter a separação desses constituintes e o primeiro resultado concreto foi o isolamento do ácido górlico, cuja presença já havia sido suspeitada, por André e JouAtTE, no óleo de $O$. echinata. Como este óleo é chamado entre os nativos da África francesa Beurre de Gorli, acordamos em manter o primeiro nome de André e Jouatte. de ácido górlico. Prosseguindo nesse trabalho analitico, pudemos enfim, em 1939, isolar mais quatro outros novos constituintes, homólogos inferiores do ácido chaulmúgrico : ácido aléprico, $\mathrm{C}_{14} \mathrm{H}_{42} \mathrm{O}_{2}$, ácido aléprico, $\mathrm{C}_{12} \mathrm{H}_{20} \mathrm{O}_{2}$, 
ácido alepréstico, $\mathrm{C}_{10} \mathrm{H}_{16} \mathrm{O}_{2}$, ácido aleprólico, $\mathrm{C}_{6} \mathrm{H}_{8} \mathrm{O}_{2}$. $\mathrm{Na}$ tabela I vêmse as constantes de todos esses ácidos.

Além desses ácidos, são encontrados, em pequenas porcentagens, outros tambem comuns a óleos diversos, como ácido oleico, ácido palmítico, etc.

Reunimos na tabela II as análises dos cinco óleos mais importantes e na tabela III as características fisicas e químicas dos mesmos, para que se a possam comprar.

A IRRITABILIDADE : suas causas e relações com o método de fabricação .

Esses ácidos graxos que acabámos de descrever, como pertencentes à série chaulmúgrica, são os agentes terapêuticos específicos conträ a lepra. Uma vez isto estabelecido, surgiu o problema da aplicação do medicamento. Este, inicialmente, era usado em natureza, ou seja, o óleo bruto, forma em que, além de irritante, ainda é de difícil injeção e absorção lenta pelo organismo. Quanto à irritação, logo se resolveu a questão por uma simples purificação, mas, quanto à maior facilidade de absorção e injeção, teve-se de recorrer à transformação do óleo em ésteres de álcoois de moléculas de tamanhos menores. Esta transformação trouxe, no entanto, uma questão seríssima, que esteve, até bem pouco tempo, a ponto de desmoralizar esta modalidade de tratamento: a grande itritabilidade desses ésteres.

TABEI.A - I

\begin{tabular}{|c|c|c|c|c|}
\hline NOME DO ÁCIDO & FORMULA & $\begin{array}{l}\text { I. DE IODO } \\
\text { (HANUS) }\end{array}$ & $\begin{array}{l}\text { PODER } \\
\text { ROTATORIO }\end{array}$ & AUTORES \\
\hline A. Chaulmúgrico. & $\mathrm{C}^{18} \mathrm{H}^{32} 0^{2}$ & 90.07 & 60.3 & Power \& Gornall (1904) \\
\hline A. Hidnocárpico. & $\mathrm{C}^{16} \mathrm{H}^{28} 0^{2}$ & 100.70 & 69.3 & $\begin{array}{c}\text { Power \& Barrowclif } \\
(1905)\end{array}$ \\
\hline A. Aléprico. & $\mathrm{C}^{14} \mathrm{H}^{24} 0^{2}$ & 113.40 & 77.1 & Cole \& Cardoso (1939) \\
\hline A. Aléprico. & $\mathrm{C}^{12} \mathrm{H}^{20} 0^{2}$ & 129.70 & 91.0 & Cole \& Cardoso (1939) \\
\hline A. Alépréstico. . & $\mathrm{C}^{10} \mathrm{H}^{16} 0^{2}$ & $151.20\left(^{*}\right)$ & $100.5\left(^{*}\right)$ & Cole \& Cardoso $(1939$ \\
\hline A. Aleprólico.. & $\mathrm{C}^{6} \mathrm{H}^{8} 0^{2}$ & $226.70\left(^{*}\right)$ & $120.5\left(^{*}\right)$ & Cole \& Cardoso (1939) \\
\hline A. Górlico. & $\mathrm{C}^{18} \mathrm{H}^{30} 0^{2}$ & 182.50 & 60.7 & Cole \& Cardoso \\
\hline
\end{tabular}

$\left({ }^{*}\right)$ Dados calculados. 
TABELA -... II

\begin{tabular}{|c|c|c|c|c|c|c|c|}
\hline & $\begin{array}{l}\text { A. CHAUL- } \\
\text { MÚGRICO }\end{array}$ & $\begin{array}{l}\text { A. IIIDNO- } \\
\text { CÁ RPICO }\end{array}$ & $\begin{array}{l}\text { A. GOR- } \\
\text { LICO }\end{array}$ & $\begin{array}{l}\text { HOMÓ- } \\
\text { LOGOS IN- } \\
\text { I'ERIORES }\end{array}$ & $\begin{array}{c}\text { AC. } \\
\text { OLEICO }\end{array}$ & $\begin{array}{l}\text { A. PALMí- } \\
\text { TICO }\end{array}$ & $\begin{array}{l}\text { NÃO IDEN- } \\
\text { TIFICADOS }\end{array}$ \\
\hline H. Wightiana & 27.0 & 48.7 & 12.2 & 3.4 & 6.5 & 1.8 & 0.4 \\
\hline $\begin{array}{r}\text { H. An the Imin- } \\
\text { tica........... }\end{array}$ & 8.7 & 67.8 & 1.4 & 0.1 & 12.3 & 7.5 & 2.2 \\
\hline T. Kurzii & 22.5 & 34.7 & 24.1 & 0.4 & 12.7 & 6.0 & 1.0 \\
\hline C. Brasiliensis & 24.4 & 45.0 & 15.4 & - & 6.3 & 6.6 & 2.3 \\
\hline O. Echinata. & 74.9 & - & 14.7 & - & 2.2 & 7.8 & 04 \\
\hline
\end{tabular}

TABEILA - III

\begin{tabular}{|c|c|c|c|c|c|}
\hline & $\begin{array}{c}\text { 1. REFRA } \\
\text { CÃA }\end{array}$ & $\begin{array}{l}\text { I. IODO } \\
\text { (HANUS) }\end{array}$ & $\begin{array}{l}\text { P. ROTA- } \\
\text { TORIO }\end{array}$ & $\begin{array}{l}\text { I. SAPONI- } \\
\text { FICAÇÃO }\end{array}$ & $\begin{array}{c}\text { ACIDER } \\
\% \text { A OLEICO }\end{array}$ \\
\hline H. Wightiana. & 1.4799 & 98.4 & 55.0 & 201.0 & 2.7 \\
\hline H. Anthelmintica. & 1.4772 & 89.2 & 49.7 & 203.3 & 2.9 \\
\hline T. Kurzii. & 1.4790 & 101.5 & 49.8 & 200.6 & 1.3 \\
\hline C. Brasiliensis.. & 1.4790 & 108.0 & 53.8 & 201.8 & 3.6 \\
\hline O. Echinata. & - & 96.4 & 51.7 & 193.7 & 4.3 \\
\hline
\end{tabular}

Mas, felizmente, a ciência poude dominar a situação e, graças a uma série de tratamentos adequados, já se podem empregar os ésteres totais, sem nenhum fenómeno de irritação ou de dor.

Os agentes causais desta irritação são vários: são especialmente produtos ácidos, resultantes da decomposição. por oxidação, dos ácidos graxos da série chaulmúgrica; são aldeidos hidro-aromáticos ; são resinas resultantes de polimerização, por oxidação lenta e ativada pela luz solar; acroleina e outros produtos derivados da ação do ácido sulfúrico sobre a glicerina do óleo; etc. Foi eloquente o resultado de uma experiência que fizémos neste sentido: partindo de ácido hidnocárpico, quimicamente puro, obtivemos os ésteres etílicos, neutralizámos e os distilámos em aparelhos Podbielniak de alta precisão. Imediatamente após, fizémos a prova intradérmica, sem outro 
tratamento para os ésteres: nenhuma irritação. Guardámos esse produto em frasco com tampa esmerilhada, procurando enchê-lo bastante, para que não restasse senão uma porção mínima de ar. Ao fim de alguns mezes, repetimos a prova intradérmica, sem fazer qualquer tratamento aos ésteres : intoleraveis. Ora, a única conclusão que se poderia tirar desses fatos é que o agente da irritação que se observou não podia ser outro senão o produto de oxidação dos constituintes dos ésteres.

Tambem procuramos averiguar si a presença dos próprios ácidos graxos constituintes, sob a forma livre, teria influência sobre o gráu de irritabilidade dos ésteres. Os resultados obtidos com soluções de ácidos graxos puros em ésteres preparados pelo método Cole \& CARDoso, mostraram que não havia alteração do gráu de irritabilidade dos mesmos.

Assim, impunham-se tratamentos tais que permitissem subtrair aos ésteres essas substâncias nocivas. Neste ponto é interessante referirmos o nosso trabalho sobre a relação entre a irritação e o método de fabricação dos ésteres, que realizamos com a colaboração de cinco médicos clínicos, no HospitalColônia de Curupaity, no Distrito Federal, Brasil. Nesse trabalho, calcado sobre os resultados obtidos em quasi mil enfermos, mostramos o gráu de irritabilidade do medicamento, que corresponde a cada fase do processo de preparação. Como não era possivel trabalhar com lotes grandes, não pudémos fazer a experiência com ésteres iodados mas sim creosotados, que não necessitam de aquecimento para a adição do creosoto.

As várias fases do nosso processo de preparação são as seguintes:

1 - Esterificação: Transformação do óleo em ésteres etílicos;

2 - Lavagem: Retirada, por meio de água quente, do alcool excedente, ácido sulfúrico e glicerina deslocada ;

3 - Distilação: Obtenção de um medicamento com a máxima porcentagem de produtos ativos terapêuticamente;

4 - Neutralização: Retirada dos ácidos produzidos na distilação, por oxidação pirogenada, pela formação dos sabões soluveis em água, que absorvem por sua vez, as demais impuresas presentes;

5 - Lavagem : Retirada dos sabões formados, até neutralidade;

6 - Vaporização: Eliminação das substâncias voláteis, como aldeidos hidro-aromáticos, e etc.

$E^{\prime}$ interessante observar o gráfico seguinte, graf. 1, em que mostramos o gráu de irritabilidade verificado praticamente, em correspondência com a fase de tratamento dos ésteres. 


\section{IRRITATION}

- LOT 9, CRUDE, UNTREATED

LOT 10, CRUDE, BLOWN

LOT 13, DISTILLED, UNTREATED

LOT 14, DISTILLED, BLOWN

LOT 11, CRUDE, NEUTRALIZED

LOT 15, DISTILLED, NEUTRALIZED

LOT 12, CRUDE, NEUTRALIZED, BLOWN

LOT 16, DISTILLED, NEUT., BLOWN 
Entretanto, o produto conserva-se ainda irritante, mesmo depois dessas seis fases de tratamento. A adição do iodo torna-o não irritante, e o creosoto o transforma em bem toleravel. E', pois, evidente, no gráfico citado, que si, em vez de ésteres creosotados, tivessemos comparado ainda com ésteres iodados, a última coluna estaria praticamente desaparecida.

Assim, no momento, os ésteres iodados a $0.5 \%$, preparados por esta técnica, representam o que ha de melhor no gênero, embora tenham a desvantagem, relativamente pequena, de produzirem uma pigmentação temporária, quando infiltrados intradermicamente. Mas apesar de estarmos seguros de que, dentro em breve, se poderão obter ésteres não irritantes sem iodo, pensamos que a presença deste auxilie a ação terapêutica do chaulmugra, uma vez que é dotado de atividade própria bem comprovada.

A TOLERÂNCIA: Neste particular julgamos necessário chamar a atenção para fatos muito importantes.

Deixando de lado as noções de terapêutica, por fugirem à nossa capacidade, queremos, no entanto, frizar alguns aspectos dos fenômenos que podem suceder ao iniciar esta nova fase de tratamentos.

Muitos cuidados são exigidos ao iniciar um tratamento, especialmente com enfermos ainda não medicados, por qualquer modo. $E^{\prime}$ forçoso distinguir a irritação devida ao medicamento, da reação oferecida pelo organismo, ao mesmo. A primeira, cujas causas e modos de evitar já estudámos mais atrás, não aparece nos ésteres iodados que preparamos. Mas, as reações da pele e do organismo, mormente a reação leprótica, devem ser observadas cuidadosamente pelos médicos.

$\mathrm{E}^{\prime}$ comum encontrarmos individuos em que, injetando intradermicamente quantidades pequenas de ésteres iodados, comprovadamente não irritantes, apresentam ao fim de pouco tempo um endurecimento no local da infiltração, às vezes, acompanhado de formação de pápula. Isto se deve, na maior parte das vezes, a uma reação do derma provocada pelos constituintes dos ésteres ou, mesmo, pelo iodo, e é devida a uma sensibilidade individual.

Os que trabalham com ésteres de chaulmugra, estão acostumados a ver. ainda, outros fenômenos que podem acometer os enfermos, principalmente depois das primeiras injeções. Lembramos que, além das precauções comuns adotadas normalmente, no caso dos novos ésteres iodados, ainda deve-se atentar bem quanto às doses a empregar, pois, além das reações normais aos constituintes dos ésteres, é possivel uma intolerância para o iodo, por parte do indivîduo. De uma maneira geral, é prudente iniciar o tratamento por doses pequenas e acompanhando a observação de cada caso, sempre que pos - 
sivel, com o maior número de dados que permitam as condições do estabelecimento, não se devendo esquecer, no entanto, as curvas térmicas nem os indices de sedimentação.

\section{BIBLIOGRAFIA}

1 - Cole $\&$ Cardoso - Analysis of Chaulmoogra Oils. I - C. Brasiliensis. - J. Am. Chem. Soc. 1938.

2 - Cale $\&$ CARdoso - Analysis of Chaulmoogra Oils. II - O. ectinata. - J. Am. Chem. Soc. 1938.

3 - Cole $\&$ Cardosa - Analysis of Chaulmoogra Oils. III - H. Wightiana. - J. Am. Chem. Soc. 1939.

4 - Cole \& Cardoso - Analysis of Chaulmoogra Oils. IV - T. Kurzii . - J. Am. Chem. Soc. 1939.

5 - Cole n Cardoso - Analysis of Chaulmoogra Oils. V - H. anthelmintica. - J. Am. Chem. Soc. 1939.

6 - Cale $\&$ Cardoso - Hydnocarpic and Chaulmoogric. Acids and Ethyl Esters. - I. Am. Chem. Soc. 1937.

7 - Cole E Cardoso - Isolation and properties of Gorlic acid, etc. - J. Am. Chem. Soc. 1938.

8 - Cole \& Cardaso - Aleppic, Aleprylic, Aleprestic and Aleprolic Acids, etc. - J. Am. Chem. Soc. 1939.

9 - Cole \& Cardoso - Purification and Esterification of Chaulmoogra Oils - Int. Jo:rr. Lep. 1936.

10 - Cole \& Cardoso - Relation of Irritation to Method of - Int. Jour Lep. 1937.

11 - Cole, H. I. - Leprosy Drugs. - Int. Lour, Lep. 1933.

12 - Cardoso, H. T. - Observações sobre o emprego do Sapucainha, etc. - Ata Médica, 1938.

13 - Cardoso, H. T. - Os constituintes ativos dos óleos de chaulmugra. etc. - Livro de homenagem aos Profs. Osório de Almeida.

14 - Schlosserger, H. - Handbuch der Experimentellen Pharmakologie. Fünfter Band, von Julius Springer, Berlin, 1937. 